\title{
Facial Angiofibromas and Periungual Fibromas in Tuberous Sclerosis
}

\author{
Hiraku Tsujimoto and Hiroya Takeoka
}

Key words: TSC, tuberous sclerosis, angiofibromas, periungual fibromas

(Intern Med 56: 127, 2017)

(DOI: 10.2169/internalmedicine.56.7431)

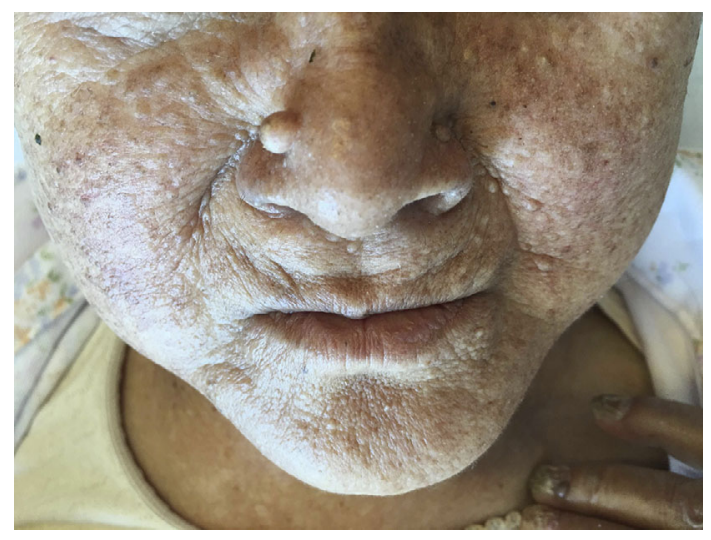

Picture 1.

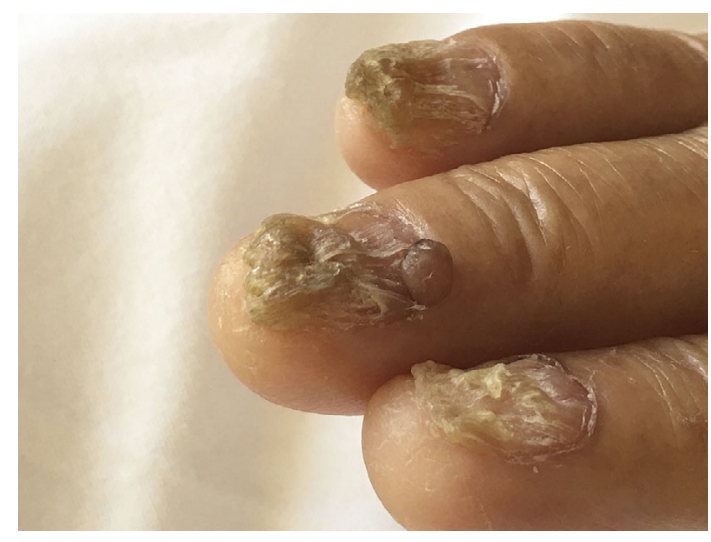

Picture 2.
A 78-year-old woman with chronic kidney disease visited our emergency department due to pain in her right flank. Abdominal computed tomography revealed perirenal hematoma and angiomyolipomas, and transcatheter arterial embolization was performed. Angiography also showed bilateral renal aneurysms. A physical examination revealed several red papules (facial angiofibromas) (Picture 1) and skincolored rubbery nodules (periungual fibromas) in the proximal nail fold of the left annular finger (Picture 2) and in the lateral nail groove of the right toe. A diagnosis of tuberous sclerosis complex (TSC) was made based on the characteristic clinical features described above $(1,2)$. Genetic testing was not performed. Further investigation revealed a retinal hamartoma but no pulmonary lymphangioleiomyomatosis. She had no history of epilepsy or intellectual disability.

With the development of novel treatment strategies, the importance of an accurate diagnosis of TSC is increasing.
The recognition of these characteristic skin features is important for making an early diagnosis.

The authors state that they have no Conflict of Interest (COI).

\section{References}

1. Schwartz RA, Fernández G, Kotulska K, Jóźwiak S. Tuberous sclerosis complex: advances in diagnosis, genetics, and management. J Am Acad Dermatol 57: 189-202, 2007.

2. Teng JMC, Cowen EW, Wataya-Kaneda M, et al. Dermatologic and dental aspects of the 2012 International Tuberous Sclerosis Complex Consensus Statements. JAMA Dermatol 150: 1095-1101, 2014.

The Internal Medicine is an Open Access article distributed under the Creative Commons Attribution-NonCommercial-NoDerivatives 4.0 International License. To view the details of this license, please visit (https://creativecommons.org/licenses/ by-nc-nd/4.0/).

Department of Nephrology, Hyogo Prefectural Amagasaki General Medical Center, Japan

Received for publication March 15, 2016; Accepted for publication May 8, 2016

Correspondence to Dr. Hiraku Tsujimoto, hira_to_ber3598@yahoo.co.jp

(C) 2017 The Japanese Society of Internal Medicine Journal Website: http://www.naika.or.jp/imonline/index.html 